\title{
Evaluation of drug incorporation into hair segments and nails by enantiomeric analysis following controlled single MDMA intakes
}

Milena M. Madry ${ }^{1}$, Andrea E. Steuer ${ }^{2}$, Cédric M. Hysek ${ }^{3}$, Matthias E. Liechti ${ }^{3}$, Markus R. Baumgartner ${ }^{1}$, Thomas Kraemer ${ }^{2^{*}}$

${ }^{1}$ University of Zurich, Zurich Institute of Forensic Medicine, Center for Forensic Hair Analysis, Zurich, Switzerland;

${ }^{2}$ University of Zurich, Zurich Institute of Forensic Medicine, Forensic Pharmacology and Toxicology, Zurich, Switzerland;

${ }^{3}$ Psychopharmacology Research, Division of Clinical Pharmacology and Toxicology, Department of Biomedicine and Department of Clinical Research, University Hospital Basel, Basel, Switzerland

$\rightarrow$ Analytical and Bioanalytical Chemistry

*Corresponding author:

Prof. Dr. Thomas Kraemer

University of Zurich

Zurich Institute of Forensic Medicine

Center for Forensic Pharmacology \& Toxicology

Winterthurerstrasse 190/52

$\mathrm{CH}-8057$ Zurich

Switzerland

Tel.: 0041446355641 ; Fax: 0041446356852

E-mail address: thomas.kraemer@irm.uzh.ch (T. Kraemer) 


\section{ABSTRACT}

Incorporation rates of the enantiomers of 3,4-methylenedioxymethamphetamine (MDMA) and its metabolite 3,4-methylenedioxyamphetamine (MDA) into hair and nails were investigated after controlled administration. Fifteen subjects without MDMA use received two doses of $125 \mathrm{mg}$ of MDMA. Hair, nail scrapings and nail clippings were collected 9-77 days after the last administration (median: 20 days). Hair samples were analyzed in segments of 1 - to $2-\mathrm{cm}$ length. After chiral derivatization with $\mathrm{N}$-(2,4-dinitro-5-fluorophenyl)-L-valinamide, MDMA and MDA diastereomers were analyzed by liquid chromatography-tandem mass spectrometry. Highest concentrations in hair segments corresponded to the time of MDMA intake. They ranged from 101 to $3,200 \mathrm{pg} / \mathrm{mg}$ and 71 to $860 \mathrm{pg} / \mathrm{mg}$ for $R$ - and S-MDMA, and 3.2 to $116 \mathrm{pg} / \mathrm{mg}$ and 4.4 to $108 \mathrm{pg} / \mathrm{mg}$ for $R$ - and S-MDA, respectively. MDMA and MDA concentrations in nail scrapings and clippings were significantly lower than in hair samples. There was no significant difference between enantiomeric ratios of R/S-MDMA and R/S-MDA in hair and nail samples (medians: 2.2-2.4 for MDMA and 0.85-0.95 for MDA). Metabolite concentration ratios of MDA to MDMA were in the same range in hair and nail samples (medians: 0.044-0.055). Our study demonstrates that administration of two representative doses of MDMA was detected in the hair segments corresponding to the time of intake based on average hair growth rates. MDMA was detected in all nail samples regardless of time passed after intake. Comparable $R / S$ ratios in hair and nail samples may indicate that incorporation mechanisms for both matrices are comparable.

Keywords: Hair analysis; nail analysis, MDMA enantiomers; controlled administration 


\section{Introduction}

The analysis of keratinzed matrices such as hair has achieved considerable importance in forensic toxicology. Main applications are long-term monitoring of drug and alcohol consumption, e.g. of drug abusers or dealers, in abstinence controls for regranting driver's license, in postmortem investigations or in drug-facilitated crimes $[1,2]$. In some cases, it is necessary to evaluate whether an individual has taken the drug on a regular basis or whether a single or sporadic intake is more likely. In order to gain time-resolved information on an individual's drug exposure, the Society of Hair Testing (SoHT) recommends analysis of hair segments of 1 - to 3-cm [3]. Based on an average growth rate of $1 \mathrm{~cm}$ per month (range $0.7-1.4 \mathrm{~cm}$ per month) the time frame of drug intake can be estimated [1]. Several reports describe the detection of drug not only in hair segments corresponding to the expected time of intake/administration but also in adjacent segments [4-7]. This may render interpretation of analysis results difficult. For amphetamines, a positive correlation after controlled administration of a low and high dose of amphetamine and methamphetamine was demonstrated within subjects but not between subjects [8].

Nails, another keratinzed matrix, are being discussed as an alternative to hair because nails also accumulate drugs [9-15]. Investigations on paired hair and nail analysis for amphetamines delineated similar [16] or higher concentrations in hair [17], but one group reported slightly higher amphetamine concentrations in fingernails compared to hair [18].

The exact mechanism for drug incorporation into hair and nails has not been identified $[1,10]$. It is nowadays recognized that drug disposition into hair takes place not only at the hair follicle but also via diffusion from sweat and sebum [1]. Studies on the incorporation pathways into nails were performed after a single dose of zolpidem $[19,20]$. The germinal nail matrix and nail bed were identified as incorporation regions 
for drugs. Furthermore, sweat presumably contributes to a large extent to drug disposition into nail as drug could already be detected in fingernail clippings 24 hours after drug intake [20]. The investigation of drug stereoisomers could hypothetically provide insights into incorporation mechanisms into hair and nail. It is recognized that enantiomers can display significantly distinct pharmacokinetic and pharmacodynamic behavior implying differences in affinity to metabolizing enzymes or receptor sites [21].

MDMA (3,4-methylenedioxymethamphetamine, ecstasy) is an illicit drug mostly traded as racemic mixture [22]. It belongs to the most prevalent drugs involved in forensic and driving under the influence cases [23-27]. MDMA is used for its entactogenic effects and stimulation of the central nervous system [28] which are mainly attributed to the S-MDMA enantiomer [29]. The $R$-enantiomer was reported to be more abundant in human tissues and fluids representing its enantioselective metabolism most likely because of the elimination of the $S$-enantiomer from plasma at a higher rate [30-33]. MDMA is primarily metabolized to 3,4-dihydroxymethamphetamine (DHMA) by the cytochrome P450 isoenzyme CYP2D6 [29], which is polymorphic [34]. MDA (3,4-methylenedioxyamphetamine) is a minor metabolite of MDMA formed by $\mathrm{N}$-demethylation [29].

The present study aims at analyzing hair and nail samples for enantiomers of MDMA and its metabolite MDA after controlled administration of two doses of $125 \mathrm{mg}$ of racemic MDMA. Segmental analysis of hair samples is performed to study whether drug detection in a hair segment can be correlated to the respective time period of MDMA intake. Nail samples are evaluated as an alternative specimen to hair when testing for single/sporadic MDMA intake. The enantioselective patterns of MDMA and MDA in hair and nails are examined to gain insights whether incorporation mechanisms into these matrices differ. To our knowledge, the present study is the 
first report on the disposition of MDMA and MDA enantiomers in hair and nail samples of non-drug using participants following controlled intake of MDMA. 


\section{Experimental}

\section{Study design and sample collection}

Hair and nail samples were obtained from a double-blind, placebo-controlled, crossover study performed at the University Hospital of Basel, Switzerland, to investigate pharmacokinetic effects of MDMA [35]. The study was conducted in accordance with the Declaration of Helsinki and International Conference on Harmonization Guidelines in Good Clinical Practice and approved by the Ethics Committee of the Canton of Basel, Switzerland, and the Swiss Agency for Therapeutic Products (Swissmedic). All participants provided written informed consent. Only subjects with no prior regular MDMA use were included. Five subjects had previously used MDMA ( $<5$ times) at least 2 months prior to the study start. Drug use during the study was excluded using repeated urine tests [35]. Subjects $(n=15)$ were administered two doses of pharmaceutical grade racemic MDMA (MDMA hydrochloride $125 \mathrm{mg}$ ) in capsules. The time interval between the two administrations was different for each subject ranging between 9 to 105 days (median: 18 days). Head hair samples, nail scrapings, and clippings were collected; 13 nail samples were from the ring finger and 3 from the big toe. Nails were wiped twice with acetone prior to sample collection. The time between last MDMA intake and sample collection ranged from 9 to 77 days (median: 20 days). All subjects were pheno- and genotyped for CYP2D6 activity [35]. Fourteen participants were extensive metabolizers and one participant (no. 1) was a poor metabolizer (Table 2).

\section{Materials}

Deuterated and undeuterated racemic standards were obtained as calibrated methanolic solutions from Lipomed (Arlesheim, Switzerland). N-(2,4-dinitro-5fluorophenyl)-L-valinamide (DNPV) for derivatization and all other chemicals were 
purchased from Sigma-Aldrich Chemie GmbH (Buchs, Switzerland). Solvents for washing, extraction and analysis by liquid chromatography-tandem mass spectrometry (LC-MS/MS), all of HPLC grade, were obtained from Sigma-Aldrich Chemie GmbH (Buchs, Switzerland). Drug-free hair and nail samples for method validation were provided by drug-naïve volunteers.

\section{Analytical methods}

\section{Hair and nail sample preparation}

Hair samples were segmented in three $1-\mathrm{cm}$ and one 2 -cm-segments from proximal to distal. Hair segments were washed separately with $2 \mathrm{~mL}$ water and $2 \mathrm{~mL}$ acetone for $2 \mathrm{~min}$, nail clippings were washed once with $1 \mathrm{~mL}$ water for $30 \mathrm{sec}$ by vortexing. On average $20 \mathrm{mg}$ hair segments, $5 \mathrm{mg}$ clippings and 1-5 mg scrapings were used for analysis. Hair and nail clippings were pulverized at $25 \mathrm{~Hz}$ for 8 min using a mixer mill (MM 200 Retsch, Switzerland). For extraction, $0.1 \mathrm{~mL}$ IS solution $(50 \mathrm{ng} / \mathrm{mL}$ ) containing MDMA-d5 and MDA-d5 and $0.9 \mathrm{~mL} \mathrm{MeOH}$ were added and samples were sonicated for $4 \mathrm{~h}$. Extracts were filtered through a 0.22 um PTFE syringe filter (BGB, Boeckten, Switzerland) and $50 \mu \mathrm{L}$ formic acid $(20 \%, \mathrm{v} / \mathrm{v})$ were added for evaporation at $50{ }^{\circ} \mathrm{C}$ under nitrogen. The residue was reconstituted in $80 \mu \mathrm{L}$ carbonate buffer (1 M, pH 9). For derivatization of MDMA and MDA $30 \mu \mathrm{L} 0.3 \% \mathrm{~N}$-(2,4-dinitro-5fluorophenyl)-L-valinamide (DNPV) in acetone were added and vials were placed in a heating block at $50^{\circ} \mathrm{C}$ for $30 \mathrm{~min}$ as previously described [36,37]. Derivatization was stopped by the addition of $20 \mu \mathrm{L}$ hydrochloric acid $(1 \mathrm{M})$. After the addition of $30 \mu \mathrm{L}$ mobile phase mixture (A: $25 \mathrm{M}$ ammonium acetate buffer $\mathrm{pH} 4$ containing $0.1 \%$ of formic acid/B: acetonitrile containing $0.1 \%$ of acetic acid; $1 / 1 ; \mathrm{v} / \mathrm{v}$ ) diastereomers of derivatized MDMA and MDA were analyzed by LC-MS/MS. 


\section{LC-MS/MS parameters}

Analytes were separated on a Phenomenex Kinetex C18 column $(100 \times 2.1 \mathrm{~mm}$, 2.6 um) using a Thermo Fisher Ultimate 3000 high performance liquid chromatography (UHPLC) system and detected by an Applied Biosystems 5500 Q Trap linear ion trap triple quadrupole mass spectrometer (Sciex, Darmstadt/ Germany) with Analyst software (Version 1.6). The following mobile phase gradient of eluent $A$ and $B$ was adjusted: $0-1 \mathrm{~min}: 2 \% \mathrm{~B} ; 1-2 \mathrm{~min}$ : increase to $40 \% \mathrm{~B} ; 2-9.3$ min: increase to $60 \%$ B; 9.3-9.5 min: increase to $98 \%$ B; $9.5-10.5$ min: holding at $98 \% \mathrm{~B} ; 10.5-10.8 \mathrm{~min}$ : decrease to $2 \% \mathrm{~B} ; 10.8-12 \mathrm{~min}$ : holding at $2 \% \mathrm{~B}$. The flow rate was $0.4 \mathrm{~mL} / \mathrm{min}$. The column temperature was maintained at $35^{\circ} \mathrm{C}$ and the injection volume was $10 \mu \mathrm{L}$. The MS instrument was operated in positive electrospray ionization and multiple reaction monitoring mode. Quantification was achieved using the most abundant transition of each precursor to the respective product ion and two MRM transitions served for identification. Further MS operation parameters were as previously reported by Steuer et al. [36].

\section{Method validation}

Standard solutions of racemic MDMA and MDA for six calibrators and quality controls (QC) at two concentration levels, low and high, were prepared separately by diluting the respective stock solution with acetonitrile. Concentrations are given in Table 1. An internal standard solution of racemic MDMA-d5 and MDA-d5 in acetonitrile was prepared at a concentration of $50 \mathrm{ng} / \mathrm{mL}$. Blank matrix of $20 \mathrm{mg}$ hair and $5 \mathrm{mg}$ nail were spiked with $100 \mathrm{uL}$ of each calibrator or QC solution. Calibration curves and quality control samples (in duplicate) were analyzed on five days. Quantitation was performed by determining the analyte to IS peak area ratios. A weighted linear regression model (1/concentration) was applied. The lower limit of quantification 
(LLOQ) and limit of detection (LOD) was chosen to be the concentration resulting in a peak height with a signal-to-noise ratio of 10 and 3 , respectively. Matrix effects were studied according to Matuszewski et al. [38]. The method was validated according to international guidelines[39].

\section{Data analysis}

Statistical analyses were carried out with Prism 6 (GraphPad Software, La Jolla, CA, USA). The nonparametric two-sided Wilcoxon matched pairs rank signed test was utilized for comparison of paired nail and hair samples results because no Gaussian distribution was observed. $\mathrm{P}$ values between $0.001-0.01$ were considered as very significantly different, $0.01-0.05$ as significantly different, $p$ values above 0.05 were not significant. 


\section{Results}

\section{Method validation}

The method was validated based on the Guidelines for Quality Control in ForensicToxicological Analyses of the GTFCh for the criteria selectivity, LOD, LLOQ, linearity of calibration, accuracy, repeatability, precision, and matrix effects [39]. Validation data are given in Table 1. Calibration curves were linear over the concentration range of 0.5 to $500 \mathrm{pg} / \mathrm{mg}$ for hair samples and 2.0 to $2000 \mathrm{pg} / \mathrm{mg}$ for nail samples. The criteria for accuracy, repeatability and precision were fulfilled. In case of S-MDMA, the deuterated analogue as IS should compensate for matrix effects which were slightly above the acceptable threshold (Table 1).

\section{Study samples}

Hair specimens were obtained from 13 participants. Hair samples were analyzed in segments of $1+1+1+2 \mathrm{~cm}$ length from proximal to distal. All subjects $(n=15)$ provided nail samples; 13 clippings from fingernails and three from toenails, and 12 scrapings from fingernails and two from toenails were collected, respectively. All samples were tested for MDMA and MDA enantiomers. The sum of MDA and MDMA enantiomers, respectively, was calculated. Concentrations for $5-\mathrm{cm}$-hair segments were calculated as an average of the four hair segments considering segment lengths. Concentrations of MDMA and MDA enantiomers and their sum in all samples are given in Figure 1 and Table 2, respectively.

\section{MDMA and MDA in hair samples}

All hair segments were tested positive for MDMA and MDA enantiomers. $R$ - and $S$ MDMA concentrations ranged from 101 to approximately $3,200 \mathrm{pg} / \mathrm{mg}$ (median: 470 $\mathrm{pg} / \mathrm{mg}$ ) and 71 to approximately $860 \mathrm{pg} / \mathrm{mg}$ (median: $221 \mathrm{pg} / \mathrm{mg}$ ), respectively 
(Figure 1A, B). The highest R-MDMA concentration (identified as outlier by Grubbs' test, $\alpha<0.01$ ) was observed in the hair sample of participant no. 1 who was henotyped a CYP2D6 poor metabolizer. R-MDMA was detected to a significantly higher extent into hair than S-MDMA (Figure 1A) whereas no difference was observed for MDA enantiomers (Figure 1B). $R$ - and S-MDA concentrations ranged from 3.2 to $116 \mathrm{pg} / \mathrm{mg}$ (median: $21 \mathrm{pg} / \mathrm{mg}$ ) and 4.4 to $108 \mathrm{pg} / \mathrm{mg}$ (median: $14 \mathrm{pg} / \mathrm{mg}$ ), respectively (Figure 1B).

In all cases, the highest concentration of each MDMA and MDA enantiomer was found in hair segments corresponding to the time of MDMA intake based on an average hair growth rate of $1 \mathrm{~cm}$ per month. Accordingly, concentrations of the sum of MDMA enantiomers in hair segments corresponding to the time of intake ranged from 173 to $3^{\prime} 770 \mathrm{pg} / \mathrm{mg}$ (median: $694 \mathrm{pg} / \mathrm{mg}$ ). The sum of concentrations of MDMA enantiomers in the four hair segments and the time of MDMA intake are presented in Figure 2. In all samples MDMA and MDA could also be detected in hair segments adjacent to the one corresponding to time of intake, however, at much lower levels. Calculated concentrations of the sum of MDMA and MDA enantiomers, respectively, in 5 -cm-segments varied from 78 to $850 \mathrm{pg} / \mathrm{mg}$ (median: $370 \mathrm{pg} / \mathrm{mg}$ ) and 3.9 to 46 $\mathrm{pg} / \mathrm{mg}$ (median: $19 \mathrm{pg} / \mathrm{mg}$ ), respectively (Table 2 ).

\section{MDMA and MDA in nail samples}

All nail clippings were tested positive for MDMA and MDA enantiomers regardless of time past MDMA intake (Table 2) (Figure 1C-F). $R$ - and S-MDMA concentrations in nail clippings ranged from 62 to approximately $990 \mathrm{pg} / \mathrm{mg}$ (median: $116 \mathrm{pg} / \mathrm{mg}$ ) and from 20 to approximately $600 \mathrm{pg} / \mathrm{mg}$ (median: $56 \mathrm{pg} / \mathrm{mg}$ ), respectively. $R$ - and $S$ MDA concentrations in nail clippings ranged from 2.0 to $28 \mathrm{pg} / \mathrm{mg}$ (median: 5.8 $\mathrm{pg} / \mathrm{mg}$ ) and from 2.9 to $48 \mathrm{pg} / \mathrm{mg}$ (median: 6.2), respectively. By far highest $R-/ S$ - 
MDMA and R-/S-MDA concentrations were detected in the toenail clipping from participant no. 12 (Figure 1C, D). All nail scrapings were tested positive for $R$ - and $S$ MDMA (Figure 1E) with concentrations ranging from 4.3 to $303 \mathrm{pg} / \mathrm{mg}$ (median: 93 $\mathrm{pg} / \mathrm{mg}$ ) and from 2.0 to $180 \mathrm{pg} / \mathrm{mg}$ (median: $44 \mathrm{pg} / \mathrm{mg}$ ). $R$ - and S-MDA could only be detected in seven of 13 scrapings at low concentrations ranging from 2.3 to 12.9 $\mathrm{pg} / \mathrm{mg}$ for both enantiomers (Figure 1F).

There was no statistical difference in the calculated sum of concentrations of MDMA and MDA enantiomers in scrapings and clippings; medians were 134 and $167 \mathrm{pg} / \mathrm{mg}$ for MDMA, and 6.3 and $12 \mathrm{pg} / \mathrm{mg}$ for MDA, respectively (Table 2). However, the sum of MDMA and MDA enantiomers were significantly lower in nail samples compared to hair samples considering a segment length of $5 \mathrm{~cm}$ (Table 2).

\section{Enantiomer ratios of MDMA and MDA in hair and nail samples}

R/S-MDMA concentration ratios were higher than 1 in all hair samples (Figure $3 \mathrm{~A}$ ). There was no significant difference between hair segments corresponding (median: 2.1) and not corresponding (median: 1.9 ) to the time of intake (Figure $3 A$ ). $R / S$ MDMA concentration ratios were higher than 1 in all nail clippings and scrapings (medians: 2.2 and 2.4, respectively) (Figure 3A). The highest $R / S-M D M A$ ratio of 5.7 and 22 was observed in a hair segment and nail scraping of participant no. 1 who was a CYP2D6 poor metabolizer (Figure 3A).

S-MDA was detected at slightly higher amounts in hair segments in most subjects, median $R / S$ ratios were 0.84 and 0.90 , respectively (Figure 3B). In nail clippings and scrapings, the median concentration ratios for $R / S-M D A$ were 0.77 and 0.95 , respectively (Figure 3B). There was no significant difference for enantiomeric ratios of MDMA and MDA in nail and hair samples (Figure 3). 
Two trends of $R / S$-MDMA concentration ratios along the four hair segments of each participant were observed: decreasing (no. 1, 2, 4, 7, 11, 12, 13, 16, 17, and 18) and increasing (no. 6 and 10) from proximal to distal, respectively (Figure 4). There was no obvious trend in samples from participant no. 14 and 18 (Figure 4).

\section{Metabolite ratios of MDA to MDMA in hair and nail samples}

MDA to MDMA ratios in corresponding and not corresponding hair segments ranged from 0.031 to 0.074 (median: 0.047 ) and from 0.029 to 0.11 (median: 0.054 ), respectively (Figure 5). In nail clippings and scrapings, metabolite ratios ranged from 0.041 to 0.13 (median: 0.055 ) and from 0.041 and 0.084 (median: 0.044), respectively (Figure 5). Overall, there was no statistical difference in metabolite concentration ratios of the sum of concentrations of MDA to MDMA enantiomers in hair segments and nail samples. 


\section{Discussion}

The analytical method applying chiral derivatization and LC-MS/MS analysis proved to be a valuable tool for the quantification of MDMA and MDA enantiomers in hair samples, nail scrapings and nail clippings. The samples were not tested for further MDMA metabolites such as DHMA and HMMA. Preliminary studies on hair samples positive for MDMA were negative for DHMA and negative for HMMA or only traces of HMMA. The method is specific and highly sensitive as low LLOQ were achieved with a sample weight of as low as $20 \mathrm{mg}$ of hair and $5 \mathrm{mg}$ of nail, respectively. In forensic investigations, it is often crucial to identify the time period in which a drug was taken. Therefore, controlled drug administration studies are needed for better understanding of disposition profiles into hair and nails.

\section{MDMA and MDA in hair samples}

As recently demonstrated, the time point of amphetamine intake could be estimated by the analysis of $0.5-\mathrm{cm}$-hair segments after controlled administration of $50 \mathrm{mg}$ amphetamine. However, only five out of nine study participants were tested positive [5]. In our study, all hair samples were positive for MDMA and MDA enantiomers after two representative intakes of $125 \mathrm{mg}$ MDMA (Table 2, Figure 1). Segmental hair analysis demonstrated that the highest enantiomeric (data not shown) and the highest calculated sum of concentrations of MDMA enantiomers (Figure 2) in hair segments correlated well with time of MDMA intake based on an average hair growth rate of $1 \mathrm{~cm}$ per month. However, the inter-individual variability in MDMA hair concentrations was large.

In seven of the 13 participants (no. 4, 6, 11, 12, 16-18) one 1-cm-segment covered the time of both MDMA doses. Five participants (no. 2, 7, 10, 13, 14) received the 
two MDMA doses with a time interval long enough to allow for monitoring by two hair segments (Figure 2). Intra-individual MDMA concentrations in these two hair segments of these participants were very similar (Figure 2, Table 2).

The hair sample of participant no. 1 was too short to cover the time of the first MDMA intake (Table 2). The highest MDMA concentration (determined as outlier by Grubbs test, $p>0.05$ ) was observed for subject no. 1 who was a CYP2D6 poor metabolizer involving a reduced elimination rate of MDMA compared to extensive metabolizers. The lowest sum of MDMA enantiomer concentrations was detected in a light brown hair sample (no. 11) (Table 2). However, there was no significant difference between (light) brown and dark brown hair samples in MDMA concentrations in 1-, 2- and 5cm-hair segments (data not shown). Also Mieczkowski and Newel who reviewed different data sets stated that there is no relationship of hair colour and MDMA concentrations in hair [40].

For CYP2D6 extensive metabolizers, the median sum of MDMA enantiomer concentration in the corresponding $1-\mathrm{cm}$ and the $5-\mathrm{cm}$-hair segments was 670 and $340 \mathrm{pg} / \mathrm{mg}$, respectively (Table 2). Applying the SoHT cut-off of $200 \mathrm{pg} / \mathrm{mg}$ for amphetamines [3], 12 of 13 hair samples with a $1-\mathrm{cm}$ - segment and 10 of 13 hair samples with a 5-cm-segment would have tested positive after two representative MDMA intakes (each $125 \mathrm{mg}$ ) within a time period of about a maximum of 3 months (94 days, median: 42 days) (Table 2). Hair samples of participants (no. 2, 7, 10, 13, 14) in which the two intakes were represented by two different hair segments would theoretically have tested positive for MDMA only after one single intake (Figure 2). Our findings demonstrate that the length of a hair segment should be considered for the interpretation of hair analysis results and application of cut-offs. 


\section{MDMA and MDA in nail samples and comparison to hair}

In two previous studies, it was demonstrated that a single drug dose is detectable in fingernail clippings $[20,19]$. The present study describes nail findings following two MDMA administrations. All nail samples were positive for MDMA enantiomers with a first and second administration ranging from 9 to 77 and 26 to 128 days, respectively, prior to sample collection. MDMA concentrations were below $500 \mathrm{pg} / \mathrm{mg}$ in all nail samples (Table 2). There was no relationship between drug concentrations in nail samples and days passed after the first or second MDMA intake. Nail incorporation takes place via nail matrix and nail bed $[20,19]$. In nail clipping drugs can be detected earlier after incorporation via nail bed than via nail matrix. Drugs can be detected in nail scrapings as soon as outgrowth of incorporated drug at the nail matrix starts reaching the exposed nail surface. Moreover, sweat/sebum contribute to drug disposition into the nail leading to drug detection already within hours after the intake. In most subjects, MDMA and MDA concentrations of enantiomers and their sum were higher in nail clippings than in scrapings (Table 2). In a recent study with cocaine users, cocaine concentrations were higher in scrapings compared to clippings which was explained by external contamination from drug residues in the environment [12]. In the present study, contamination can be excluded as intake was performed in the scope of a controlled study. Lower levels in scrapings may be explained by drug extraction during daily hygiene as the nail surface which is collected for scrapings is more exposed to drug extraction [12].

Our study included the analysis of 13 fingernail and 3 toenail samples. In two toenail samples (no. 10,16), concentrations of MDMA and MDA enantiomers and their sum were in the same range as in fingernail samples (Table 2). Highest MDMA and MDA concentrations were detected in the toenail clipping of participant no. 12 . Interestingly, the MDMA concentration in the respective toenail scraping was not 
significantly higher compared to other samples and also MDA was not detectable (Figure 1C-F, Table 2). Because toenails grow slower than fingernails $[10,11,9]$, they represent a longer window of detection for drugs. Therefore, higher drug concentrations in toenail samples may be explained by drug use long time prior to the study. The $5-\mathrm{cm}$ long hair sample of participant no. 12 was too short to verify this assumption.

In 8 of 13 subjects, the sum of concentrations of MDMA enantiomers were lower in nail clippings compared to the 5 -cm-hair segment, in two participants comparable concentrations were found (Table 2). Cirimele et al. reported for one case slightly higher MDMA and MDA concentrations in fingernail scrapings compared to hair [18]. It should be noted that hair and nail samples represent different time frames: about 5 months based on an average growth rate if the hair sample is $5 \mathrm{~cm}$ long, for nail clippings a median window of detection of 3.5 months was determined [20]. To our knowledge, there is no report on windows of detection for scrapings. Further, the bizonal drug incorporation mechanism into nails makes time-resolved analysis impossible unless clippings are collected continuously over a longer period [20]. Despite of these limitations, our findings illustrate that nail clippings can be suitably used for retrospective monitoring of drug history alternatively to hair, especially in cases where hair is not long enough or cosmetically treated, as a positive result for MDMA and MDA proves MDMA intake. Nail scrapings seem less suitable as not all samples were positive for the metabolite MDA after two single MDMA intakes.

\section{Enantiomer ratios of MDMA and MDA in hair and nail samples}

$R$-MDMA concentrations were significantly higher than S-MDMA concentrations in all hair and nail samples whereas no difference was observed for concentrations of MDA enantiomers (Figure 1, Figure 3). Participant no. 1, who was a CYP2D6 poor 
metabolizer, had the highest $R / S$-MDMA ratio in the hair segment corresponding to the time of intake and the nail scraping whereas the ratio in the nail clipping was in the range of the extensive CYP2D6 metabolizers (Figure 3A). To our knowledge, there are two reports on chiral analysis of MDMA and MDA in hair samples from suspected or self-declared MDMA users [41-43]. Enantiomeric ratios for MDMA and MDA from our controlled intake study are in concordance with hair findings reported by Martins et al. from a study with self-declared MDMA users after controlled MDMA administration [41]. Fallon et al. demonstrated that plasma and urine concentrations of $R$-MDMA exceed those of S-MDMA at all time-points analyzed over $24 \mathrm{~h}$ after administration whereas S-MDA plasma concentrations exceeded those of $R$-MDA [31]. Our study results display the same trend for hair and nail samples.

Similar enantiomeric ratios of MDMA and MDA in hair, nail clippings and scrapings may suggest that drug disposition into these three matrices are comparable.

Within subject comparison revealed two patterns for R/S-MDMA concentration ratios along the hair segments: a decreasing or increasing trend from proximal to distal segments. The decreasing and increasing trend corresponded to decreasing and increasing sum of concentrations of MDMA enantiomers along the hair segments, respectively, except for participant no. 18 (Figure 3 and 4). The highest R/S-MDMA ratio in the proximal (participant no.1, 12, 16, 4, 17, 2, 11,13,7) or distal (participant no. 6 and 10) segments corresponded to recent or earlier MDMA administration, respectively (Figure 4). In case of recent MDMA intake lower R/S-MDMA ratios in distal segments may be explained by sweat incorporation. There was no trend for MDA enantiomeric ratios along the hair segments (data not shown).

Participant no. 14 received the two MDMA doses with a time interval of 2 months, which was monitored by significantly increased MDMA concentrations in both 
corresponding hair segments (Figure 2). The longer time interval of intakes resulted in comparable $R / S-M D M A$ ratios along the hair segments (Figure 4B).

\section{Metabolite ratios of MDA to MDMA in hair and nail samples}

The determination of metabolite to parent drug ratios was recommended for the discrimination between drug intake and external contamination of a hair sample [44] and has proved to be useful [45-47]. For this purpose, metabolite ratios have to be determined after controlled intake of drug in a scope where contamination can be excluded. As routine analysis is typically achiral, the sum of the respective enantiomer concentrations were used for the metabolite ratios. In our study, median ratios of MDA to MDMA concentrations in hair following administration of pharmaceutical racemic MDMA were 0.047 in corresponding and 0.054 in not corresponding hair segments (Figure 5). Other authors reported similar metabolic ratios after street MDMA use $(0.04$ to 0.06$)[48,49]$ or controlled administration (< $0.09)[41]$.

\section{Conclusion}

A suitable analytical method for the chiral analysis of MDMA and MDA in hair and nail samples was presented. The study demonstrates that administrations of two representative single doses of MDMA can be detected in the hair segments corresponding to the time of intake and in all nail samples. As all nail clippings were positive for MDMA and the metabolite MDA irrespective of days passed after intake, clippings appears a suitable alternative to hair for prove of MDMA intake. Since no significant difference was observed for enantiomeric ratios in hair and nail samples incorporation mechanisms into both keratinized matrices may be comparable. 


\section{References}

1. Pragst $F$, Balikova MA (2006) State of the art in hair analysis for detection of drug and alcohol abuse. Clinica Chimica Acta 370 (1-2):17-49. doi:doi: DOI:

10.1016/j.cca.2006.02.019

2. Wille SMR, Baumgartner MR, Di Fazio V, Samyn N, Kraemer T (2014) Trends in drug testing in oral fluid and hair as alternative matrices. Bioanalysis (submitted)

3. Cooper G, Kronstrand R, Kintz P (2012) Society of Hair Testing guidelines for drug testing in hair. Forensic Sci Int 218 (1-3):20-24. doi:10.1016/j.forsciint.2011.10.024

4. Henderson GL, Harkey MR, Zhou C, Jones RT, Jacob P (1996) Incorporation of Isotopically Labeled Cocaine and Metabolites into Human Hair: 1. Dose-Response Relationships. Journal of Analytical Toxicology 20 (1):1-12. doi:10.1093/jat/20.1.1

5. Jakobsson G, Kronstrand R (2014) Segmental analysis of amphetamines in hair using a sensitive UHPLC-MS/MS method. Drug Testing and Analysis 6 (S1):22-29. doi:10.1002/dta.1637

6. Kintz P (2013) Issues about axial diffusion during segmental hair analysis. Ther Drug Monit 35 (3):408-410

7. Rothe M, Pragst F, Spiegel K, Harrach T, Fischer K, Kunkel J (1997) Hair concentrations and self-reported abuse history of 20 amphetamine and ecstasy users. Forensic Scilnt 89 (1-2):111-128

8. Polettini A, Cone EJ, Gorelick DA, Huestis MA (2012) Incorporation of methamphetamine and amphetamine in human hair following controlled oral methamphetamine administration. Analytica Chimica Acta 726 (0):35-43. doi:10.1016/j.aca.2012.01.042

9. Cappelle D, Yegles M, Neels H, van Nuijs AL, De Doncker M, Maudens K, Covaci A, Crunelle CL (2014) Nail analysis for the detection of drugs of abuse and pharmaceuticals: a review. Forensic Toxicol:1-25

10. Garside D (2008) Drugs-of-Abuse in Nails. In: Jenkins AJ (ed) Drug Testing in Alternate Biological Specimens. Forensic Science And Medicine. Humana Press, Totowa, NJ, USA, pp 43-65

11. Palmeri A, Pichini S, Pacifici R, Zuccaro P, Lopez A (2000) Drugs in nails Physiology, pharmacokinetics and forensic toxicology. Clin Pharmacokinet 38 (2):95110

12. Madry MM, Steuer AE, Vonmoos M, Quednow BB, Baumgartner MR, Kraemer T (2014) Retrospective monitoring of long-term recreational and dependent cocaine use in toenail clippings/scrapings as an alternative to hair. Bioanalysis 6(23):31833196

13. Krumbiegel F, Hastedt M, Tsokos M (2014) Nails are a potential alternative matrix to hair for drug analysis in general unknown screenings by liquidchromatography quadrupole time-of-flight mass spectrometry. Forensic Sci Med Pathol:1-8. doi:10.1007/s12024-014-9588-x 
14. Morini L, Colucci M, Ruberto M, Groppi A (2012) Determination of ethyl glucuronide in nails by liquid chromatography tandem mass spectrometry as a potential new biomarker for chronic alcohol abuse and binge drinking behavior. Analytical and Bioanalytical Chemistry 402 (5):1865-1870. doi:10.1007/s00216-011$5609-8$

15. Liechti ME, Geyer MA, Hell D, Vollenweider FX (2001) Effects of MDMA (ecstasy) on prepulse inhibition and habituation of startle in humans after pretreatment with citalopram, haloperidol, or ketanserin. Neuropsychopharmacology 24 (3):240-252. doi:10.1016/S0893-133X(00)00199-8

16. Suzuki O, Hattori H, Asano M (1984) Nails as useful materials for detection of methamphetamine or amphetamine abuse. Forensic Sci Int 24 (1):9-16. doi:doi: DOI: 10.1016/0379-0738(84)90146-4

17. Lin D-L, Yin R-M, Liu H-C, Wang C-Y, Liu RH (2004) Deposition Characteristics of Methamphetamine and Amphetamine in Fingernail Clippings and Hair Sections. Journal of Analytical Toxicology 28 (6):411-417. doi:10.1093/jat/28.6.411

18. Cirimele V, Kintz P, Mangin $P$ (1995) Detection of amphetamines in fingernails: an alternative to hair analysis. Archives of Toxicology 70 (1):68-69

19. Hang C, Ping X, Min S (2013) Long-term follow-up analysis of zolpidem in fingernails after a single oral dose. Analytical and Bioanalytical Chemistry 405(23):7281-7289. doi:10.1007/s00216-013-7188-3

20. Madry MM, Steuer AE, Binz TM, Baumgartner MR, Kraemer T (2014) Systematic investigation of the incorporation mechanisms of zolpidem in fingernails. Drug Testing and Analysis 6(6):533-541

21. Rentsch KM (2002) The importance of stereoselective determination of drugs in the clinical laboratory. Journal of biochemical and biophysical methods 54 (1):1-9

22. (EMCDDA) EMCfDaDA (2015) Methylenedioxymethamphetamine (MDMA or 'Ecstasy') drug profile.

23. Pilgrim JL, Gerostamoulos D, Drummer OH (2011) Deaths Involving MDMA and the Concomitant Use of Pharmaceutical Drugs. Journal of Analytical Toxicology 35 (4):219-226. doi:10.1093/anatox/35.4.219

24. Milroy CM (2011) "Ecstasy" associated deaths: what is a fatal concentration ? Analysis of a case series. Forensic Sci Med Pathol 7 (3):248-252.

doi:10.1007/s12024-010-9220-7

25. Senna MC, Augsburger M, Aebi B, Briellmann TA, Donze N, Dubugnon JL, Iten PX, Staub C, Sturm W, Sutter K (2010) First nationwide study on driving under the influence of drugs in Switzerland. Forensic Scilnt 198 (1-3):11-16. doi:S03790738(10)00066-6 [pii];10.1016/j.forsciint.2010.02.014 [doi]

26. Schifano F, Corkery J, Deluca P, Oyefeso A, Ghodse AH (2006) Ecstasy (MDMA, MDA, MDEA, MBDB) consumption, seizures, related offences, prices, dosage levels and deaths in the UK (1994-2003). Journal of psychopharmacology 20 (3):456-463. doi:10.1177/0269881106060147 
27. Liechti ME (2015) Novel psychoactive substances (designer drugs): overview and pharmacology of modulators of monoamine signalling. Swiss Med Wkly 145:w14043

28. Green AR, Mechan AO, Elliott JM, O'Shea E, Colado MI (2003) The pharmacology and clinical pharmacology of 3,4-methylenedioxymethamphetamine (MDMA, "ecstasy"). PharmacolRev 55 (3):463-508

29. de la Torre R, Farre M, Roset PN, Pizarro N, Abanades S, Segura M, Segura J, Cami J (2004) Human pharmacology of MDMA: pharmacokinetics, metabolism, and disposition [review]. TherDrug Monit 26 (2):137-144

30. Schwaninger AE, Meyer MR, Barnes AJ, Kolbrich-Spargo EA, Gorelick DA, Goodwin RS, Huestis MA, Maurer HH (2012) Stereoselective urinary MDMA (ecstasy) and metabolites excretion kinetics following controlled MDMA administration to humans. Biochemical Pharmacology 83 (1):131-138. doi:http://dx.doi.org/10.1016/j.bcp.2011.09.023

31. Fallon JK, Kicman AT, Henry JA, Milligan PJ, Cowan DA, Hutt AJ (1999) Stereospecific analysis and enantiomeric disposition of 3, 4-

methylenedioxymethamphetamine (Ecstasy) in humans. ClinChem 45 (7):1058-1069

32. Peters FT, Samyn N, Wahl M, Kraemer T, de Boeck G, Maurer HH (2003) Concentrations and Ratios of Amphetamine, Methamphetamine, MDA, MDMA, and MDEA Enantiomers determined in Plasma Samples From Clinical Toxicology and Driving Under the Influence of Drugs Cases by GC-NICI-MS. JAnalToxicol 27 (8):552-559

33. Moore KA, Mozayani A, Fierro MF, Poklis A (1996) Distribution of 3,4methylenedioxymethamphetamine (MDMA) and 3,4-methylenedioxyamphetamine (MDA) stereoisomers in a fatal poisoning. Forensic Scilnt 83 (2):111-119

34. Sachse C, Brockmöller J, Bauer S, Roots I (1997) Cytochrome P450 2D6 variants in a Caucasian population: allele frequencies and phenotypic consequences. American Journal of Human Genetics 60 (2):284-295

35. Hysek CM, Simmler LD, Schillinger N, Meyer N, Schmid Y, Donzelli M, Grouzmann E, Liechti ME (2014) Pharmacokinetic and pharmacodynamic effects of methylphenidate and MDMA administered alone or in combination. Int $\mathrm{J}$ Neuropsychoph 17 (3):371-381. doi:Doi 10.1017/S1461145713001132

36. Steuer AE, Schmidhauser C, Liechti ME, Kraemer T (2014) Development and validation of an LC-MS/MS method after chiral derivatization for the simultaneous stereoselective determination of methylenedioxy-methamphetamine (MDMA) and its phase I and II metabolites in human blood plasma. Drug Testing and Analysis:n/an/a. doi:10.1002/dta. 1740

37. Nakanishi K, Katagi M, Zaitsu K, Shima N, Kamata H, Miki A, Kato H, Harada KI, Tsuchihashi $\mathrm{H}$, Suzuki K (2012) Simultaneous enantiomeric determination of MDMA and its phase I and phase II metabolites in urine by liquid chromatography-tandem mass spectrometry with chiral derivatization. Anal Bioanal Chem 404 (8):2427-2435. doi:DOI 10.1007/s00216-012-6385-9 
38. Matuszewski BK, Constanzer ML, Chavez-Eng CM (2003) Strategies for the assessment of matrix effect in quantitative bioanalytical methods based on HPLCMS/MS. Anal Chem 75 (13):3019-3030

39. Musshoff F, Skopp G, Pragst F, Sachs H (2009) Appendix C of the GTFCh Guidelines for Quality Control in Forensic-Toxicological Analyses. Quality requirements for the analysis of hair samples.

40. Mieczkowski T, Newel R (2000) Statistical examination of hair color as a potential biasing factor in hair analysis. Forensic Scilnt 107 (1-3):13-38

41. Martins LF, Yegles M, Samyn N, Ramaekers JG, Wennig R (2007) Time-resolved hair analysis of MDMA enantiomers by GC/MS-NCI. Forensic Sci Int 172 (2-3):150155. doi:10.1016/j.forsciint.2007.01.008

42. Strano-Rossi S, Botrè F, Bermejo AM, Tabernero MJ (2009) A rapid method for the extraction, enantiomeric separation and quantification of amphetamines in hair. Forensic Sci Int 193 (1-3):95-100.

doi:http://dx.doi.org/10.1016/j.forsciint.2009.09.016

43. Tagliaro F, Manetto G, Bellini S, Scarcella D, Smith FP, Marigo M (1998) Simultaneous chiral separation of 3,4-methylenedioxymethamphet- amine, 3-4methylenedioxyamphetamine, 3,4-methylenedioxyethylam- phetamine, ephedrine, amphetamine and methamphetamine by capillary electrophoresis in uncoated and coated capillaries with native beta-cyclodextrin as the chiral selector: preliminary application to the analysis of urine and hair. Electrophoresis 19 (1):42-50

44. Society of Hair Testing: Statement of the Society of Hair Testing concerning the examination of drugs in human hair (1997). Forensic Sci Int 84:3-6

45. Romano G, Barbera N, Spadaro G, Valenti V (2003) Determination of drugs of abuse in hair: evaluation of external heroin contamination and risk of false positives. Forensic Sci Int 131 (2-3):98-102

46. Madry MM, Rust KY, Guglielmello R, Baumgartner MR, Kraemer T (2012) Metabolite to parent drug concentration ratios in hair for the differentiation of tramadol intake from external contamination and passive exposure. Forensic Sci Int 223 (1-3):330-334. doi:http://dx.doi.org/10.1016/j.forsciint.2012.10.012

47. Romano G, Barbera N, Lombardo I (2001) Hair testing for drugs of abuse: evaluation of external cocaine contamination and risk of false positives. Forensic Sci Int $123(2-3): 119-129$

48. Cooper G, Allen DL, Scott KS, Oliver JS, Ditton J, Smith ID (2000) Hair analysis: self-reported use of" speed" and" ecstasy" compared with laboratory findings. Journal of Forensic Sciences 45 (2):400-406

49. Pichini S, Poudevida S, Pujadas M, Menoyo E, Pacifici R, Farré M, de la Torre R (2006) Assessment of Chronic Exposure to MDMA in a Group of Consumers by Segmental Hair Analysis. Ther Drug Monit 28 (1):106-109 


\section{FIGURES}
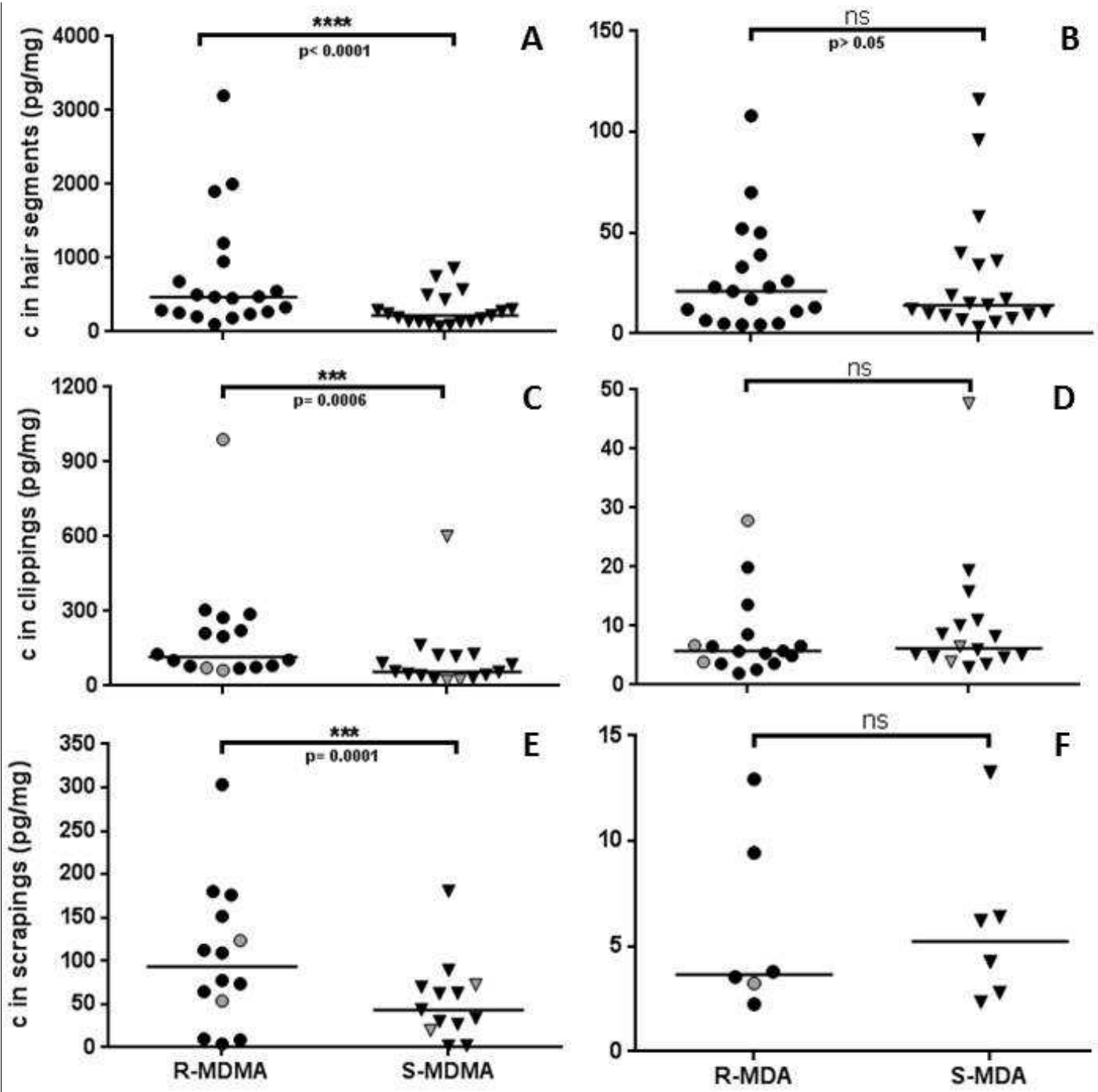

Figure 1. Measured R/S-MDMA and R/S-MDA concentrations in hair segments corresponding to the calculated time of intake $(A+B)$, in nail clippings $(C+D)$ and nail scrapings $(E+F)$; black circle/ triangle $=$ specimen from fingernail, grey circle/ triangle $=$ specimen from toenail. Statistical analysis by paired, two-tailed, non-parametric t-test; $p<0.001$ : very significant $\left({ }^{* \star *}\right), p>0.05$ : not significant (ns). 

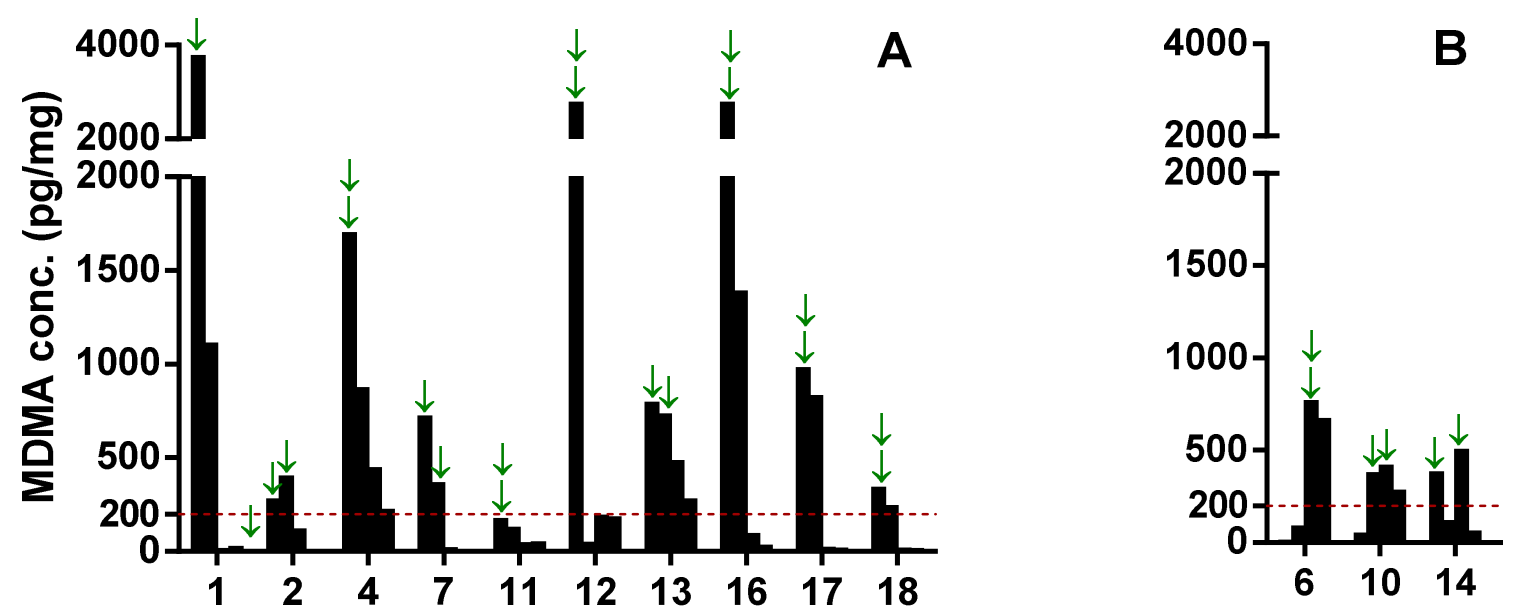

Figure 2. Calculated sum of concentrations of MDMA enantiomers in four hair segments $(1+1+1+2 \mathrm{~cm}$, from proximal to distal) from participants with recent $(A)$, earlier (participant no. 6 and 10) and recent with earlier (participant no. 14) intake (B). Green arrows indicate hair segments corresponding to the time of MDMA intake. Red dotted line: SoHT cut-off for MDMA in hair samples. Participant no. 1 was phenotyped a CYP2D6 poor metabolizer.
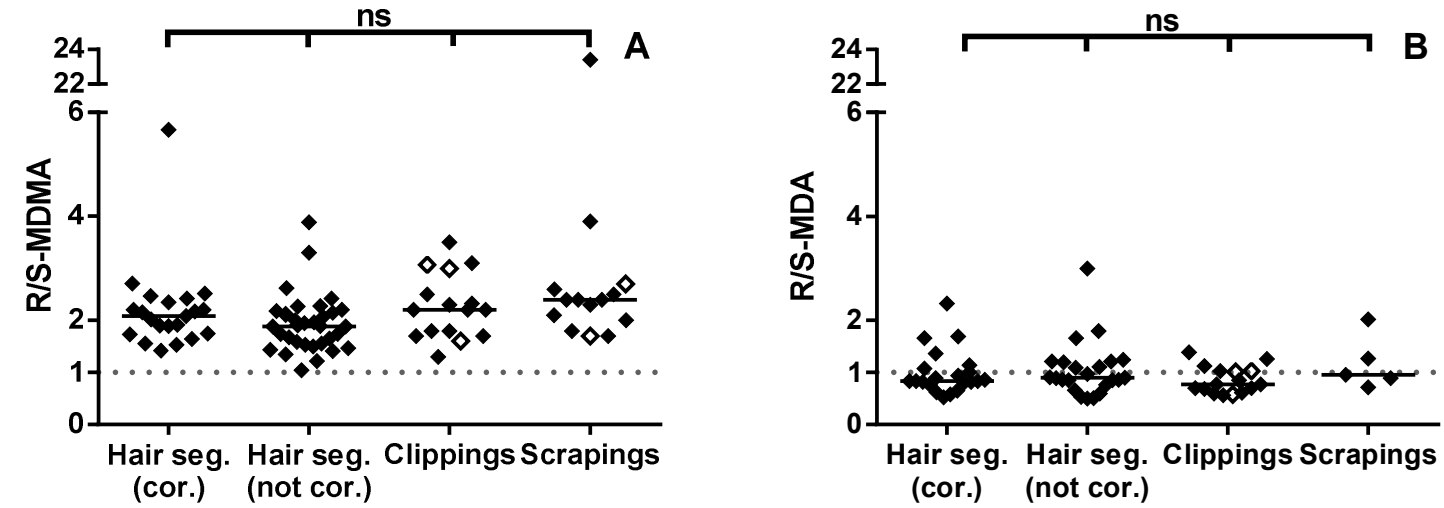

Figure 3. Enantiomeric concentration ratios of $R / S$-MDMA (A) and $R / S-M D A(B)$ in hair segments (seg.) corresponding (cor.) and not corresponding (not cor.) to the time of intake, nail clippings and scrapings; black square = fingernail, white square= toenail. Statistical analysis by parametric one-way ANOVA test; $p>0.05$ : not significant (ns). Dotted line represents racemic 1:1 ratio. Outlier with $R / S$-MDMA ratio of 5.6 and 23 (A) was phenotyped a CYP2D6 poor metabolizer (participant no. 1). 

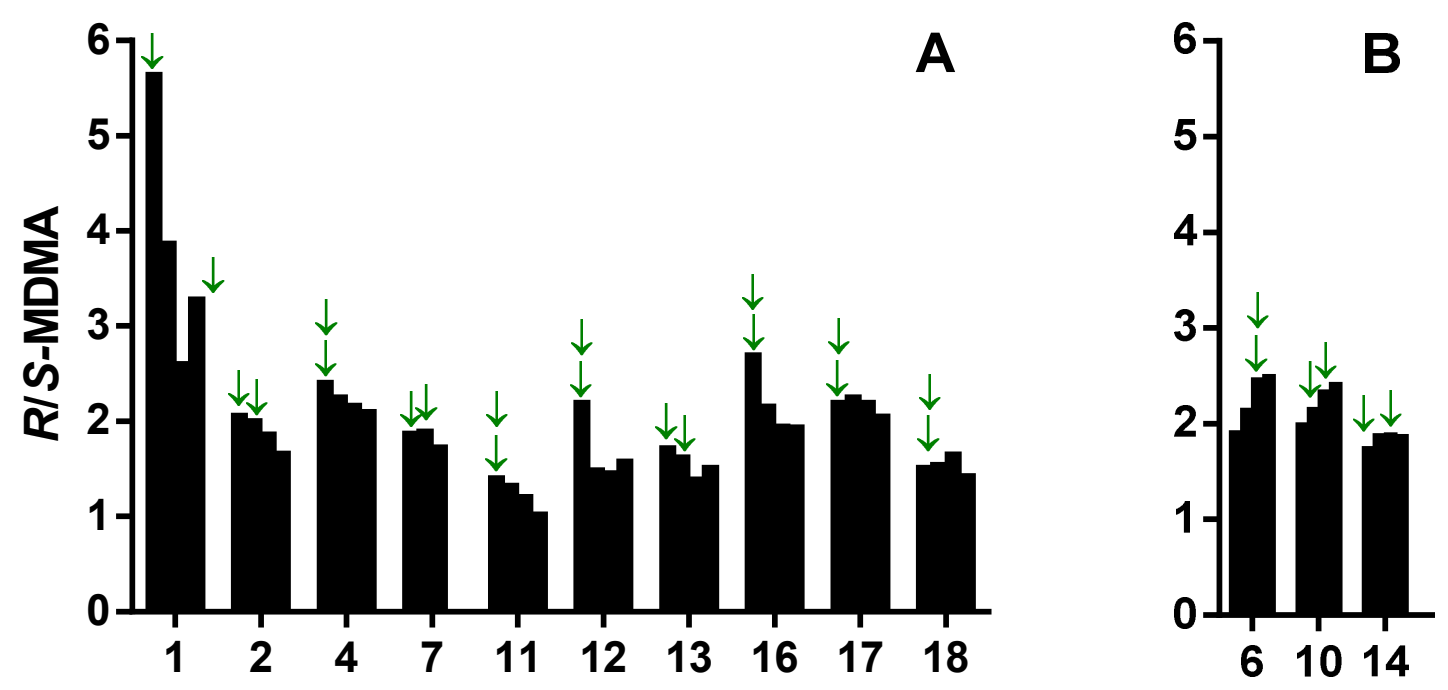

Figure 4. Enantiomeric R/S-MDMA concentration ratios in four hair segments $(1+1+1+2 \mathrm{~cm}$, from proximal to distal) from participants with recent (A), earlier (B; no. 6 and 10 ) and recent with earlier intake (B; no. 14) intake. Green arrows indicate hair segments corresponding to the time of MDMA intake. Participant no. 1 was phenotyped a CYP2D6 poor metabolizer.

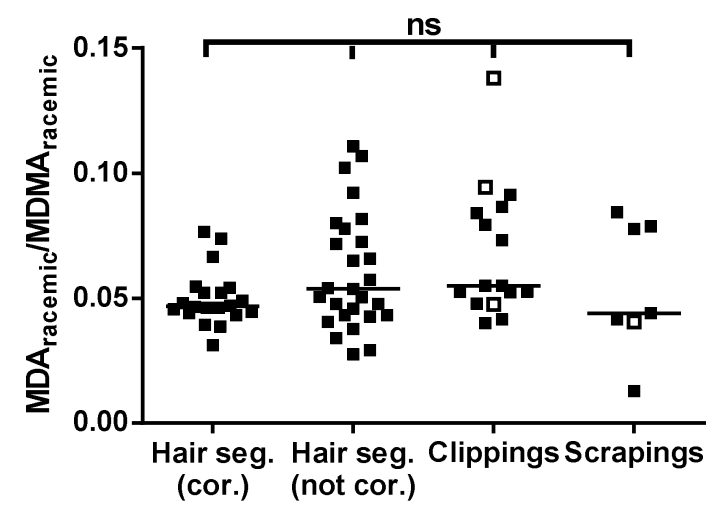

Figure 5. Metabolic ratios of sum of concentrations of MDA and MDMA enantiomers in hair segments corresponding (cor.) and not corresponding (not cor.) to the time of intake, nail clippings and scrapings; black square = fingernail, white square $=$ toenail. Statistical analysis by non-paired, two-tailed, non-parametric t-test; $p>0.05$ : not significant (ns). 


\section{TABLES}

Table 1. Validation data for analysis of nail and hair samples.

\begin{tabular}{|c|c|c|c|c|c|c|c|c|}
\hline $\begin{array}{l}\text { Analyte } \\
\text { (IS) }\end{array}$ & \multicolumn{2}{|c|}{$\begin{array}{c}\text { R-MDMA } \\
(\mathrm{R}-\mathrm{MDMA}-\mathrm{D} 5)\end{array}$} & \multicolumn{2}{|c|}{$\begin{array}{c}\text { S-MDMA } \\
\text { (S-MDMA-D5) }\end{array}$} & \multicolumn{2}{|c|}{$\begin{array}{c}\text { R-MDA } \\
(\mathrm{R}-\mathrm{MDA}-\mathrm{D} 5)\end{array}$} & \multicolumn{2}{|c|}{$\begin{array}{c}\text { S-MDA } \\
(\text { S-MDA-D5) }\end{array}$} \\
\hline \multicolumn{9}{|l|}{ Hair analysis } \\
\hline $\mathrm{LOD}(\mathrm{pg} / \mathrm{mg})$ & \multicolumn{8}{|c|}{0.125} \\
\hline LLOQ $(\mathrm{pg} / \mathrm{mg})$ & \multicolumn{8}{|c|}{0.5} \\
\hline Linearity (pg/mg) & \multicolumn{8}{|c|}{$0.5 ; 50 ; 200 ; 300 ; 400 ; 500$} \\
\hline QC level & LOW & HIGH & LOW & HIGH & LOW & HIGH & LOW & $\mathrm{HIGH}$ \\
\hline QC conc. $(\mathrm{pg} / \mathrm{mg})$ & 0.625 & 450 & 0.625 & 450 & 0.625 & 450 & 0.625 & 450 \\
\hline Accuracy (\%) & -9.8 & 6.1 & -15.9 & 6.7 & -10.5 & 5.2 & -1.3 & -2.4 \\
\hline Repeatability (\%) & 8.6 & 4.7 & 4.2 & 4.7 & 3.7 & 5.1 & 8.0 & 5.8 \\
\hline Precision (\%) & 8.6 & 5.8 & 11.7 & 5.6 & 11.7 & 9.4 & 8.6 & 8.5 \\
\hline $\begin{array}{l}\text { ME, mean } \\
\pm \mathrm{SD}(\%)\end{array}$ & $\begin{array}{c}97 \\
\pm 2.8\end{array}$ & $\begin{array}{r}114 \\
\pm 3.7 \\
\end{array}$ & $\begin{array}{r}106 \\
\pm 6.4 \\
\end{array}$ & $\begin{array}{r}134 \\
\pm 9.8 \\
\end{array}$ & $\begin{array}{r}124 \\
\pm 2.8\end{array}$ & $\begin{array}{r}127 \\
\pm 7.3 \\
\end{array}$ & $\begin{array}{c}124 \\
\pm 5.4\end{array}$ & $\begin{array}{c}111 \\
\pm 17.6 \\
\end{array}$ \\
\hline \multicolumn{9}{|l|}{ Nail analysis } \\
\hline LOD (pg/mg) & \multicolumn{8}{|c|}{0.5} \\
\hline LLOQ $(\mathrm{pg} / \mathrm{mg})$ & \multicolumn{8}{|c|}{2.0} \\
\hline Calibrators (pg/mg) & \multicolumn{8}{|c|}{$2.0 ; 200 ; 800 ; 1200 ; 1600 ; 2000$} \\
\hline QC level & LOW & HIGH & LOW & HIGH & LOW & HIGH & LOW & HIGH \\
\hline QC conc. (pg/mg) & 2.5 & 1800 & 2.5 & 1800 & 2.5 & 1800 & 2.5 & 1800 \\
\hline Accuracy (\%) & 6.5 & -1.8 & 0.1 & -1.2 & 3.9 & 0.2 & -6.1 & 2.5 \\
\hline Repeatability (\%) & 7.4 & 3.7 & 14.3 & 7.5 & 6.3 & 4.2 & 6.1 & 6.8 \\
\hline Precision (\%) & 11.2 & 11.8 & 15.0 & 14.9 & 7.5 & 14.3 & 8.5 & 10.6 \\
\hline $\begin{array}{l}\text { ME, mean } \\
\pm S D(\%)\end{array}$ & $\begin{array}{r}116 \\
\pm 4.1\end{array}$ & $\begin{array}{r}106 \\
\pm 2.1\end{array}$ & $\begin{array}{r}126 \\
\pm 6.2\end{array}$ & $\begin{array}{r}130 \\
\pm 2.3\end{array}$ & $\begin{array}{r}122 \\
\pm 9.4\end{array}$ & $\begin{array}{r}107 \\
\pm 4.1\end{array}$ & $\begin{array}{c}113 \\
\pm 14.4\end{array}$ & $\begin{array}{r}103 \\
\pm 6.1\end{array}$ \\
\hline
\end{tabular}

$\mathrm{IS}=$ internal standard; $\mathrm{LOD}=$ limit of detection; $\mathrm{LLOQ}=$ limit of quantification; $\mathrm{QC}=\mathrm{Quality}$ control; conc. $=$ concentration 
Table 2. Measured concentrations of MDMA and MDA enantiomers and calculated sum of concentrations of MDMA and MDA enantiomers in hair segments and fingernail (and/or toenail) scrapings and clippings

\begin{tabular}{|c|c|c|c|c|c|c|c|c|c|c|c|c|c|c|c|c|c|c|}
\hline \multirow{4}{*}{$\begin{array}{c}\text { Subject } \\
\text { no. }\end{array}$} & \multirow{4}{*}{$\begin{array}{l}\text { Days } \\
\left.*^{1}\right)\end{array}$} & \multirow{4}{*}{$\begin{array}{c}\text { Days } \\
*^{2} \text { ) }\end{array}$} & \multirow{4}{*}{$\begin{array}{l}\text { Hair } \\
\text { colour }\end{array}$} & \multicolumn{9}{|c|}{ Hair segments } & \multicolumn{6}{|c|}{ Nail samples } \\
\hline & & & & \multicolumn{15}{|c|}{ MDMA concentration (pg/mg) } \\
\hline & & & & \multicolumn{2}{|c|}{$\begin{array}{l}\text { A }(0-1 \mathrm{~cm}) \\
\text { proximal }\end{array}$} & \multicolumn{2}{|c|}{$\mathrm{B}(1-2 \mathrm{~cm})$} & \multicolumn{2}{|c|}{$C(2-3 \mathrm{~cm})$} & \multicolumn{2}{|c|}{$\begin{array}{c}\mathrm{D}(3-5 \mathrm{~cm}) \\
\text { distal }\end{array}$} & \multirow{2}{*}{$\begin{array}{c}0-5 \mathrm{~cm} \\
\text { (calc.) } \\
\text { Sum } R+S \\
\text { (calc.) }\end{array}$} & \multicolumn{3}{|c|}{ scrapings } & \multicolumn{3}{|c|}{ clippings } \\
\hline & & & & $R$ & $S$ & $R$ & $S$ & $R$ & $S$ & $R$ & $S$ & & $R$ & $S$ & $\begin{array}{c}\text { Sum } R+S \\
\text { (calc.) }\end{array}$ & $R$ & $S$ & $\begin{array}{c}\text { Sum } R+S \\
\text { (calc.) }\end{array}$ \\
\hline 01 (PM) & 128 & 23 & dark brown & $\approx 3200$ & $\approx 570$ & $\approx 880$ & 227 & 9.3 & 3.5 & 19 & 5.7 & 980 & 10 & $<\mathrm{LOQ}$ & 10 & 306 & 86 & 392 \\
\hline 02 (EM) & 55 & 41 & brown & 187 & 90 & 271 & 134 & 77 & 41 & 3.7 & 2.2 & 160 & 8.8 & 2.2 & 11.0 & 105 & 48 & 153 \\
\hline 03 (EM) & 41 & 14 & $\mathrm{~N} / \mathrm{A}$ & \multicolumn{9}{|c|}{ N/A } & 303 & 180 & 483 & 222 & 127 & 349 \\
\hline 04 (EM) & 39 & 28 & dark brown & $\approx 1200$ & 497 & $\approx 610$ & 266 & 303 & 139 & 151 & 71 & 650 & 151 & & 214 & 199 & 91 & 290 \\
\hline 06 (EM) & 94 & 77 & dark brown & 7.1 & 3.7 & 59 & 28 & $\approx 550$ & 221 & 478 & 190 & 310 & 113 & 44 & 157 & 127 & 55 & 182 \\
\hline 07 (EM) & 42 & 17 & brown & 470 & 249 & 238 & 125 & 11 & 6.5 & \multicolumn{2}{|c|}{$\mathrm{N} / \mathrm{A}$} & 367 & 65 & 27 & 92 & 81 & 44 & 125 \\
\hline 09 (EM) & 67 & 46 & $\mathrm{~N} / \mathrm{A}$ & \multicolumn{9}{|c|}{$\mathrm{N} / \mathrm{A}$} & 4.3 & 2.0 & 6.3 & 103 & 42 & 145 \\
\hline 10 (EM) & 64 & 49 & brown & 32 & 16 & 257 & 119 & 292 & 124 & 199 & 82 & 220 & $\left.54^{*^{3}}\right)$ & $\left.20 *^{3}\right)$ & 74 & $\left.72 *^{3}\right)$ & $\left.23^{*^{3}}\right)$ & 95 \\
\hline 11 (EM) & 26 & 9 & light brown & 101 & 71 & 72 & 54 & 25 & 20 & 24 & 23 & 78 & & & N/A & 75 & 57 & 132 \\
\hline 12 (EM) & 28 & 17 & dark brown & $\approx 1900$ & $\approx 860$ & 28 & 18 & 113 & 77 & 111 & 70 & $\sim 640$ & $124 *^{3}$ ) & $\left.72 *^{3}\right)$ & 196 & $\left.990 *^{3}\right)$ & $\left.600 *^{3}\right)$ & 1590 \\
\hline 13 (EM) & 49 & 13 & light brown & 500 & 291 & 454 & 276 & 281 & 199 & 166 & 109 & 460 & 180 & 89 & 269 & 211 & 123 & 334 \\
\hline 14 (EM) & 78 & 23 & brown & 242 & 139 & 76 & 40 & 331 & 174 & 40 & 21 & 210 & 77 & 34 & 111 & 70 & 33 & 103 \\
\hline \multirow[t]{2}{*}{16 (EM) } & \multirow[t]{2}{*}{35} & \multirow[t]{2}{*}{14} & \multirow[t]{2}{*}{ dark brown } & $\approx 2000$ & $\approx 750$ & $\approx 950$ & 437 & 60 & 30 & 19 & 10 & $\sim 850$ & 74 & 30 & 104 & 80 & 27 & 107 \\
\hline & & & & & & & & & & & & & & N/A & & $\left.62 *^{3}\right)$ & $\left.20 *^{3}\right)$ & 82 \\
\hline 17 (EM) & 35 & 17 & dark brown & $\approx 680$ & 305 & $\approx 570$ & 253 & 13 & 5.9 & 9.3 & 4.5 & 370 & 176 & 70 & 246 & 275 & 118 & 393 \\
\hline 18 (EM) & 35 & 20 & dark brown & 206 & 134 & 148 & 95 & 9.8 & 5.9 & 7.7 & 5.4 & 120 & 109 & 62 & 171 & 288 & 163 & 451 \\
\hline & & & & & & & & & & & MDA CO & centration & $\mathrm{pg} / \mathrm{mg}$ ) & & & & & \\
\hline 01 (PM) & 128 & 23 & dark brown & 116 & 50 & 38 & 21 & 1.0 & $<\mathrm{LOQ}$ & 1.7 & $<\mathrm{LOQ}$ & 46 & nd & nd & nd & 20 & 16 & 36 \\
\hline 02 (EM) & 55 & 41 & brown & 7.5 & 4.4 & 9 & 6.6 & 2.7 & 2.4 & 1.2 & nd & 6.7 & nd & nd & nd & 3.6 & 4.7 & 8.4 \\
\hline 03 (EM) & 41 & 14 & N/A & & & & & $\mathrm{N} / \mathrm{l}$ & & & & & nd & 6.2 & & 5.8 & 8.2 & 14.0 \\
\hline 04 (EM) & 39 & 28 & dark brown & 34 & 33 & 19 & 21 & 11 & 13 & 5.3 & 5.9 & 28 & nd & nd & nd & 6.6 & 8.6 & 15.2 \\
\hline 06 (EM) & 94 & 77 & dark brown & $<\mathrm{LOQ}$ & nd & 3.1 & 2.6 & 19 & 23 & 14 & 17 & 16 & 3.5 & 2.8 & 6.3 & 3.6 & 6.0 & 9.6 \\
\hline 07 (EM) & 42 & 17 & brown & 17 & 21 & 7.4 & 8.8 & 1.5 & 0.5 & & $/ \mathrm{A}$ & 19 & nd & nd & nd & 5.7 & 5.1 & 11 \\
\hline 09 (EM) & 67 & 46 & $\mathrm{~N} / \mathrm{A}$ & & & & $\mathrm{N} /$ & & & & & & nd & nd & nd & 5.3 & 5.2 & 11 \\
\hline 10 (EM) & 64 & 49 & brown & 1.8 & 1.4 & 9.5 & 4.4 & 11 & 12 & 9.3 & 11 & 12 & $\left.3.2^{*^{3}}\right)$ & $\mathrm{nd}^{*^{3}}$ ) & 3.2 & $\left.6.7 *^{3}\right)$ & $6.5^{\left.*^{3}\right)}$ & 13 \\
\hline 11 (EM) & 26 & 9 & light brown & 3.2 & 5.1 & 2.5 & 4.7 & 1.1 & 1.1 & 0.6 & 1.2 & 3.9 & & N/A & & 2.6 & 4.7 & 7.3 \\
\hline 12 (EM) & 28 & 17 & dark brown & 58 & 70 & 1.0 & $<\mathrm{LOQ}$ & 3.9 & 4.3 & 3.4 & 4.0 & 29 & $n d^{3}$ ) & $\mathrm{nd}^{\left.*^{3}\right)}$ & $n d^{3}$ ) & $\left.28 *^{3}\right)$ & $48^{\left.*^{3}\right)}$ & 76 \\
\hline 13 (EM) & 49 & 13 & light brown & 15 & 26 & 12 & 23 & 6.9 & 14 & 3.7 & 5.6 & 21 & 9.5 & 13.2 & 22.7 & 6.5 & 11 & 18 \\
\hline 14 (EM) & 78 & 23 & brown & 6.8 & 11 & 2.2 & 3.7 & 10 & 13 & 1.3 & 1.5 & 9.9 & 2.3 & 2.4 & 4.7 & 2.0 & 2.9 & 4.9 \\
\hline 16 (EM) & 35 & 14 & dark brown & 96 & 108 & 40 & 52 & 3.0 & 4.0 & 1.6 & 1.4 & 61 & 3.8 & 4.3 & 8.1 & 4.9 & 3.5 & 8.4 \\
\hline & & & & & & & & & & & & & & $\mathrm{N} / \mathrm{A}$ & & $\left.3.9 *^{3}\right)$ & $\left.3.9 *^{3}\right)$ & 7.8 \\
\hline 17 (EM) & 35 & 17 & dark brown & 36 & 39 & 34 & 32 & 1.0 & 0.8 & 0.7 & $<\mathrm{LOQ}$ & 29 & 12.9 & 6.4 & 19.3 & 14 & 19 & 33 \\
\hline 18 (EM) & 35 & 20 & dark brown & 5.7 & 4.9 & 4.4 & 2.7 & nd & 0.6 & nd & 1.0 & 3.9 & nd & nd & nd & 8.6 & 10 & 19 \\
\hline
\end{tabular}


